\title{
Frequency of sunburn in Queensland adults: still a burning issue
}

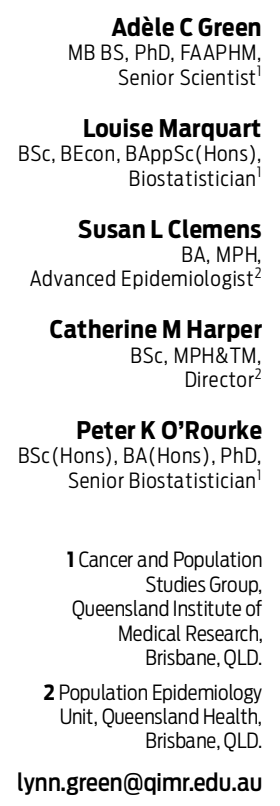

MJA 2013; 198: 431-434 doi: $10.5694 /$ mjal2.11499
T he impact of skin cancer is disproportionately high due to its extraordinarily high incidence in white populations compared with other cancers. In the United States, skin cancer costs an estimated US $\$ 2$ billion annually. ${ }^{1}$ In Australia, skin cancers cost more than other major cancers. ${ }^{2}$ Sunburn, the acute inflammation caused by excessive exposure to solar ultraviolet radiation, is a determinant of all major skin cancers. ${ }^{3}$ An estimated 1.3 million skin cancer cases were due to excessive sun exposure ${ }^{4}$ in the US in 2003, and a regional study in Texas calculated the economic impact of sunburn as over US\$10 million annually through lost work and treatment costs. ${ }^{5}$ Sunburn prevalence (at least one sunburn in the past year) in white US adults aged 18-29 years has been constant for a decade at $66 \% .{ }^{6}$ Men, the young and high-income groups appear susceptible. $^{7}$ In Australia, weekend sunburn prevalence was $9 \%$ overall in Victoria in $2002^{8}$ but in Queensland in $2004,70 \%$ of surveyed residents aged $20-75$ years reported sunburn in the past year. ${ }^{9}$

Sunburn is of crucial public health importance as a key preventable and common risk factor for skin cancer. We assessed frequency of sunburn and associated factors in Queensland in two surveys in 2009 and 2010.

\section{Methods}

The Queensland Health Population Epidemiology Unit conducted selfreported health status surveys from January to March 2009 (SRHS 2009) and from October 2009 to February 2010 (SRHS 2010) using computerassisted telephone interviews ${ }^{10}$ with approval from the Queensland Health Central Office Human Research Ethics Committee. The target population sourced by randomdigit-dialling was Queensland households with a person aged $\geqslant 18$ years (SRHS 2009) or $\geqslant 16$ years

\section{Abstract \\ Objective: To assess the current frequency of sunburn, a preventable risk factor for skin cancer, among Queensland adults.}

Design and setting: Cross-sectional population-based surveys of 16473 residents aged $\geqslant 18$ years across Queensland in 2009 and 2010.

Main outcome measures: Proportion of the adult population reporting sunburn (skin reddening lasting 12 hours or more) during the previous weekend, by age, sex and other risk factors.

Results: One in eight men and one in 12 women in Queensland reported being sunburnt on the previous weekend. Age up to 65 years was the strongest predictor of sunburn: eg, people aged 18-24 years were seven times more likely (adjusted odds ratio [OR], 7.35; 95\% Cl, 5.09-10.62) and those aged 35-44 years were five times more likely (adjusted OR, 5.22) to report sunburn compared with those aged $\geqslant 65$ years. Not having a tertiary education and being in the workforce were also significantly associated with sunburn. Those who had undertaken any physical activity the previous week were more likely to be sunburnt than those who were physically inactive. Sunburn was significantly less likely among people who generally took sun-protective measures in summer. Sunburn was not related to location of residence, socioeconomic disadvantage, skin colour, body weight or current smoking status.

Conclusions: Sunburn remains a public health problem among Queensland residents, especially those under 45 years of age. Sun-safe habits reduce sunburn risk, but advice must be integrated with health promotion messages regarding physical activity to reduce the skin cancer burden while maintaining active wellbeing.

(SRHS 2010). From each selected household, one eligible resident was asked to participate. Response rates were calculated as the number of completed interviews expressed as a percentage of the number of eligible persons contacted.

A structured interview using a scripted questionnaire covered demographic and risk factors including sunburn on the previous weekend. Sunburn was defined as any reddening of the skin lasting longer than 12 hours after sun exposure. Other information collected included age, sex, height and weight, education, marital and employment status, fruit and vegetable intake, smoking, general use of sun protection and physical activity based on the Active Australia instrument. ${ }^{11}$ For analysis, employment status was categorised as employed, retired or student/carer/unemployed; fruit/ vegetable consumption as meeting daily recommended levels $(\geqslant 2$ serves of fruit and $\geqslant 5$ serves of vegetables); ${ }^{12}$ smoking as daily or not; and physical activity as none, insufficient (1-4 sessions of walking/ moderate/vigorous activity and/or $<150$ minutes total, weekly), or sufficient to meet national guidelines ${ }^{13}$ $(\geqslant 5$ sessions for $\geqslant 150$ minutes total, weekly). Statistical Local Areas of residence were classified by the Accessibility/Remoteness Index of Australia $^{14}$ (ARIA+), the Socio-Economic Indexes For Areas ${ }^{15}$ (SEIFA) and geographically (North, Central, South and West Queensland).

Identical variables from the 2009 and 2010 surveys were pooled for adults aged $\geqslant 18$ and weighted by age, sex and Queensland Health Service District distribution using 2008 estimated resident population data for Queensland (Australian Bureau of Statistics, http://www. abs.gov.au/AUSSTATS/abs@.nsf/ DetailsPage/3235.02008?OpenDocument) to minimise bias due to overor underrepresentation of any demographic group, and by the number of in-scope people and fixed telephone lines per household to minimise selection bias. Weighted proportions (with 95\% confidence intervals) of the population who reported being sunburnt the previ- 
1 Prevalence of being sunburnt on the previous weekend, by sex and age

\begin{tabular}{|c|c|c|c|c|c|c|}
\hline \multirow[b]{2}{*}{ Age group } & \multicolumn{3}{|c|}{ Men } & \multicolumn{3}{|c|}{ Women } \\
\hline & Total no. & No. sunburnt & Proportion $(95 \% \mathrm{Cl}) *$ & Total no. & No. sunburnt & Proportion $(95 \% \mathrm{Cl}) *$ \\
\hline $18-24$ years & 459 & 102 & $22.0 \%(17.7 \%-27.0 \%)$ & 373 & 60 & $15.3 \%(11.2 \%-20.6 \%)$ \\
\hline 25-34 years & 932 & 173 & $16.9 \%(14.1 \%-20.1 \%)$ & 1038 & 123 & $13.1 \%(10.5 \%-16.3 \%)$ \\
\hline $35-44$ years & 1431 & 235 & $15.4 \%(13.3 \%-17.8 \%)$ & 1540 & 156 & $10.5 \%$ (8.7\%-12.6\%) \\
\hline $45-54$ years & 1647 & 198 & $12.7 \%(10.7 \%-14.9 \%)$ & 1763 & 159 & $8.0 \%(6.6 \%-9.8 \%)$ \\
\hline $55-64$ years & 1743 & 139 & $8.1 \%(6.7 \%-9.8 \%)$ & 1659 & 63 & $4.0 \%(3.0 \%-5.2 \%)$ \\
\hline$\geqslant 65$ years & 1938 & 54 & $2.2 \%(1.6 \%-3.0 \%)$ & 1950 & 35 & $1.8 \%(1.2 \%-2.6 \%)$ \\
\hline All age groups & 8150 & 901 & $12.9 \%$ (11.9\%-14.0\%) & 8323 & 596 & $8.6 \%(7.7 \%-9.6 \%)$ \\
\hline
\end{tabular}

ous weekend were calculated, stratified by age and sex. Univariate and multivariate logistic regressions adjusting for age $(18-24,25-34,35-$ $44,45-54,55-64, \geqslant 65$ years), sex, education (bachelor degree or higher, diplomas/certificates/trade, no qualifications) and physical activity - were undertaken to estimate the association between sunburn and risk factors, using Stata SE, version 11.0 (StataCorp).

\section{Results}

Response rates were 57\% (7537/ $13289)$ and $65 \%(8938 / 13857)$ in the 2009 and 2010 surveys, respectively. Pooling of the two surveys (results did not differ) provided a total of 16473 Queensland adults. Of these, $15 \%$ lived in North, $20 \%$ in Central, $63 \%$ in South, and $2 \%$ in West Queensland, while 55\% lived in major cities, 39\% in regional areas and $6 \%$ in remote areas, based on census data of the estimated resident population of Queensland. Of the 8150 men, 901 (12.9\%, weighted; 95\% CI, 11.9\%-14.0\%) reported being sunburnt the previous weekend, compared with 596 of 8323 women $(8.6 \%$, weighted; $95 \%$ CI, $7.7 \%-9.6 \%$ ) (Box 1). Peak weighted prevalence of 22\% (102/ 459) was among young men aged 18-24 years. There was a clear trend of decreasing sunburn prevalence with increasing age in both sexes $(P<0.001)$, such that sunburn was least common among participants aged $\geqslant 65$ years (men, $2.2 \%$, weighted [54/1938]; women, $1.8 \%$, weighted [35/1950]) (Box 1).
After adjustment, the strongest predictor of sunburn was youth: people aged 18-24 years were seven times more likely to report being sunburnt than those aged $\geqslant 65$ years, although adults aged 45-64 years were also at significantly higher risk of being sunburnt than those $\geqslant 65$ years (Box 2 ).

Other sunburn predictors were male sex, not having a tertiary education, and being in the workforce. People who had undertaken physical activity in the previous week, regardless of frequency or duration, were more likely to be sunburnt than those who did not. People who undertook the recommended level of physical activity had twice the odds of sunburn of inactive people, while those who undertook one to four sessions were also at risk (Box 2). Those who generally used sunscreen in summer tended to be less likely to be sunburnt than non-users (adjusted OR, 0.86) (Box 2). Although hat-wearing per se was not associated with sunburn after adjustment for confounding factors (Box 2), those who usually sought shade or wore protective clothing in summer also had significantly lower odds of sunburn than those who did not, and respondents' most common explanation for sunburn was failure to use clothing or sunscreen protection (SRHS 2010 only; data not shown).

No other factors, including marital status, body weight, smoking, fruit/ vegetable consumption, location of residence, socioeconomic status (Box 2) or skin colour (SRHS 2010 only; data not shown) were associated with sunburn.

\section{Discussion}

If sunburn in Australia were reduced, decreased rates of skin cancer would follow. ${ }^{3}$ Queensland has the highest melanoma rates in Australia, and Australia and New Zealand have the highest rates in the world. ${ }^{16}$ We have shown that around one in 10 Queensland adults report being sunburnt on the weekend in summer. Men were about $50 \%$ more likely than women to experience sunburn and adults aged under 65 years were more likely to be sunburnt than those aged 65 years and over. Youngest adults (aged 18-24 years) were sunburnt most often. While people in the workforce and those without tertiary qualifications are more likely to report sunburn than others, this probably reflects sunburn in leisure more than work hours, since weekend sunburn prevalence was assessed. Physical activity was also associated with sunburn.

Our results are broadly consistent with a 2004 Queensland survey showing young age and male sex greatly increase odds of sunburn. ${ }^{9}$ An earlier analysis of SRHS 2010 data also showed that people engaging in physical activity were more likely to experience sunburn on the previous weekend and during the past year, especially those who undertook $\geqslant 7$ hours of activity per week. ${ }^{17}$ Sun-safety and physical activity promotion messages must be integrated, acknowledging the importance of both for health and wellbeing.

This study was drawn from adults of all ages across Queensland but excluded households without fixed 
2 Characteristics of people sunburnt on the previous weekend, showing prevalence distribution and associated odds ratio (OR) of being sunburnt

\begin{tabular}{|c|c|c|c|c|c|}
\hline Characteristic & Proportion sunburnt $(95 \% \mathrm{Cl}$ ) & Weighted OR* $(95 \% \mathrm{Cl})$ & $P$ & Adjusted $\mathrm{OR}^{\dagger}(95 \% \mathrm{Cl})$ & $P$ \\
\hline Age, years & & & $<0.001$ & & $<0.001$ \\
\hline $18-24$ & $18.8 \%(15.7 \%-22.3 \%)$ & $11.46(8.18-16.04)$ & & 7.35 (5.09-10.62) & \\
\hline $25-34$ & $15.0 \%(13.0 \%-17.2 \%)$ & $8.74(6.45-11.85)$ & & $5.95(4.23-8.36)$ & \\
\hline $35-44$ & $12.9 \%(11.5 \%-14.5 \%)$ & $7.36(5.52-9.83)$ & & $5.22(3.78-7.22)$ & \\
\hline $45-54$ & $10.3 \%(9.03 \%-11.6 \%)$ & $5.67(4.23-7.60)$ & & $4.04(2.91-5.60)$ & \\
\hline $55-64$ & $6.1 \%(5.2 \%-7.1 \%)$ & $3.20(2.35-4.36)$ & & $2.23(1.59-3.14)$ & \\
\hline$\geqslant 65$ & $2.0 \%(1.5 \%-2.5 \%)$ & $1^{\ddagger}$ & & $1^{\ddagger}$ & \\
\hline Sex & & & $<0.001$ & & $<0.001$ \\
\hline Female & $8.6 \%(7.7 \%-9.6 \%)$ & $1^{\ddagger}$ & & $1^{\ddagger}$ & \\
\hline Male & $12.9 \%(11.9 \%-14.0 \%)$ & $1.57(1.34-1.82)$ & & $1.47(1.25-1.72)$ & \\
\hline Highest level of education & & & $<0.001$ & & $<0.001$ \\
\hline Bachelor degree or higher & $9.1 \%(7.9 \%-10.6 \%)$ & $1^{\ddagger}$ & & $1^{\ddagger}$ & \\
\hline Diploma/certificate/trade & $13.2 \%(12.0 \%-14.5 \%)$ & $1.51(1.24-1.84)$ & & $1.56(1.27-1.91)$ & \\
\hline No post-school qualifications & $9.2 \%(8.2 \%-10.4 \%)$ & $1.01(0.82-1.25)$ & & $1.28(1.03-1.61)$ & \\
\hline Employment status & & & $<0.001$ & & $<0.001$ \\
\hline Employed & $13.3 \%(12.4 \%-14.3 \%)$ & $1^{\ddagger}$ & & $1^{\ddagger}$ & \\
\hline Retired & $2.1 \%(1.6 \%-2.6 \%)$ & $0.14(0.11-0.18)$ & & $0.46(0.32-0.64)$ & \\
\hline Student/carer/unemployed & $10.2 \%(8.4 \%-12.2 \%)$ & $0.74(0.59-0.92)$ & & $0.71(0.56-0.91)$ & \\
\hline Marital status & & & 0.005 & & 0.85 \\
\hline Married/de facto & $10.0 \%(9.3 \%-10.8 \%)$ & $\eta^{\ddagger}$ & & $1^{\ddagger}$ & \\
\hline Not married/separated/widow & $12.4 \%(10.9 \%-14.1 \%)$ & $1.27(1.07-1.51)$ & & $0.98(0.81-1.20)$ & \\
\hline Fruit and vegetable intake ${ }^{\xi}$ & & & 0.08 & & 0.63 \\
\hline Not meeting recommendations & $10.9 \%(10.2 \%-11.7 \%)$ & $1.30(0.97-1.74)$ & & $1.08(0.79-1.46)$ & \\
\hline Meeting recommendations & $8.6 \%(6.7 \%-11.1 \%)$ & $1^{\ddagger}$ & & $1^{\ddagger}$ & \\
\hline Smoking status & & & $<0.001$ & & 0.16 \\
\hline Not a daily smoker & $10.2 \%(9.4 \%-11.0 \%)$ & $1^{\ddagger}$ & & $1^{\ddagger}$ & \\
\hline Daily smoker & $13.7 \%(11.9 \%-15.6 \%)$ & $1.40(1.17-1.67)$ & & $1.15(0.95-1.39)$ & \\
\hline Body mass index, $\mathrm{kg} / \mathrm{m}^{2}$ & & & 0.83 & & 0.22 \\
\hline$<18.5$ & $12.9 \%(8.2 \%-19.6 \%)$ & $1.28(0.76-2.14)$ & & $1.33(0.76-2.31)$ & \\
\hline $18.5-24.9$ & $10.4 \%(9.2 \%-11.6 \%)$ & $1^{\ddagger}$ & & $1^{\ddagger}$ & \\
\hline $25-29.9$ & $11.2 \%(10.0 \%-12.4 \%)$ & $1.09(0.91-1.29)$ & & $1.20(1.00-1.45)$ & \\
\hline $30-39.9$ & $10.8 \%(9.3 \%-12.4 \%)$ & $1.04(0.85-1.27)$ & & $1.24(1.00-1.53)$ & \\
\hline$\geqslant 40$ & $10.7 \%(6.8 \%-16.4 \%)$ & $1.04(0.62-1.72)$ & & $1.23(0.72-2.09)$ & \\
\hline Physical activity & & & $<0.001$ & & $<0.001$ \\
\hline No physical activity & $5.8 \%(4.4 \%-7.5 \%)$ & $1^{\ddagger}$ & & $1^{\ddagger}$ & \\
\hline Insufficient time or sessions & $10.2 \%(9.0 \%-11.5 \%)$ & $1.85(1.36-2.53)$ & & $1.66(1.21-2.29)$ & \\
\hline Sufficient time and sessions & $13.6 \%(12.5 \%-14.7 \%)$ & $2.57(1.90-3.46)$ & & $2.13(1.57-2.89)$ & \\
\hline Use sunscreen in summer & & & 0.99 & & 0.07 \\
\hline No & $10.7 \%(9.7 \%-11.8 \%)$ & $1^{\ddagger}$ & & $1^{\ddagger}$ & \\
\hline Yes & $10.7 \%(9.8 \%-11.7 \%)$ & $1.00(0.86-1.16)$ & & $0.86(0.73-1.01)$ & \\
\hline Wear hat in summer & & & 0.77 & & 0.11 \\
\hline No & $10.9 \%(9.5 \%-12.6 \%)$ & $1^{\ddagger}$ & & $1^{\ddagger}$ & \\
\hline Yes & $10.7 \%(9.9 \%-11.5 \%)$ & $0.97(0.81-1.16)$ & & $1.17(0.96-1.41)$ & \\
\hline SEIFA & & & 0.36 & & 0.44 \\
\hline Disadvantaged & $10.2 \%(8.9 \%-11.7 \%)$ & $1.05(0.82-1.35)$ & & $1.20(0.92-1.56)$ & \\
\hline Quintile 2 & $11.2 \%(9.7 \%-12.8 \%)$ & $1.16(0.90-1.50)$ & & $1.18(0.90-1.54)$ & \\
\hline Quintile 3 & $10.5 \%(9.1 \%-12.0 \%)$ & $1.08(0.84-1.39)$ & & $1.12(0.87-1.46)$ & \\
\hline Quintile 4 & $12.0 \%(10.4 \%-13.9 \%)$ & $1.26(0.98-1.63)$ & & $1.29(0.99-1.68)$ & \\
\hline Advantaged & $9.8 \%(8.2 \%-11.6 \%)$ & $7^{\ddagger}$ & & $1^{\ddagger}$ & \\
\hline ARIA+ & & & 0.47 & & 0.53 \\
\hline Major cities & $10.4 \%(9.4 \%-11.5 \%)$ & $1^{\ddagger}$ & & $1^{\ddagger}$ & \\
\hline Inner regional & $11.8 \%(10.3 \%-13.5 \%)$ & $1.15(0.95-1.39)$ & & $1.16(0.95-1.42)$ & \\
\hline Outer regional & $10.6 \%(9.3 \%-12.1 \%)$ & $1.02(0.85-1.22)$ & & $1.05(0.87-1.27)$ & \\
\hline Remote/very remote & $10.2 \%(8.4 \%-12.3 \%)$ & $0.97(0.76-1.24)$ & & $1.01(0.78-1.31)$ & \\
\hline Geographical location** & & & 0.15 & & 0.41 \\
\hline North Queensland & $10.9 \%(9.6 \%-12.5 \%)$ & $1.04(0.87-1.24)$ & & $1.00(0.83-1.21)$ & \\
\hline West Queensland & $12.8 \%(11.2 \%-14.6 \%)$ & $1.24(1.03-1.49)$ & & $1.16(0.95-1.41)$ & \\
\hline Central Queensland & $10.9 \%(9.5 \%-12.6 \%)$ & $1.04(0.86-1.25)$ & & $1.11(0.91-1.35)$ & \\
\hline South Queensland & $10.6 \%(9.7 \%-11.6 \%)$ & $1^{\ddagger}$ & & $1^{\ddagger}$ & \\
\hline
\end{tabular}

ARIA+ = Accessibility/Remoteness Index for Australia. ${ }^{14}$ SEIFA = Socio-Economic Indexes For Areas. ${ }^{15} *$ Population-weighted (based on 2008 estimated resident Queensland population, http://www.abs.gov.au/AUSSTATS/abs@.nsf/DetailsPage/3235.02008?OpenDocument) analyses unadjusted.

† Population-weighted (based on 2008 estimated resident Queensland population) analyses adjusted for age, sex, physical activity and education level. $\ddagger$ Reference group. \$ National Health and Medical Research Council dietary guidelines for Australian adults. ${ }^{12}$ q Department of Health and Ageing national physical activity guidelines for adults. ${ }^{13} * *$ North Queensland = Cairns and Hinterland, Mackay, Torres Strait Island, Townsville; West Queensland = Cape York, Central West, Mt Isa, South West Queensland; Central Queensland = Central Queensland, Darling Downs/West Moreton and Wide Bay; South

Queensland = Sunshine Coast, Metro North, Metro South and Gold Coast. 
telephones, and restricted detail was available about timing of physical activity in relation to sunburn. However, we have shown that despite half a century of campaigns, sun protection in Queensland remains far from optimal. Vigilance to avoid sunburn is essential among active adults. Men still are more likely to be sunburnt and need targeted encouragement to practise prevention measures. By experiencing sunburn, often repeatedly, ${ }^{9}$ Queenslanders are driving their already high risk of skin cancer higher. ${ }^{3}$ In Victoria, where the SunSmart program originated, prevention programs have recently stalled. ${ }^{8}$ Redoubled efforts are required through television and other media campaigns to improve sun-protection and ultimately reduce skin cancer.

Competing interests: Adèle Green has received past project support from L'Oréal Recherche.

Received 6 Oct 2012, accepted 24 Feb 2013

1 Hirst NG, Gordon LG, Scuffham PA, Green AC. Lifetime cost-effectiveness of skin cancer prevention through promotion of daily sunscreen use. Value Health 2012; 15: 261-268.

2 Staples MP, Elwood M, Burton RC, et al. Nonmelanoma skin cancer in Australia: the 2002 national survey and trends since 1985. Med J Aust 2006; 184: 6-10.

3 International Agency for Research on Cancer. IARC monographs on the evaluation of carcinogenic risks to humans. Solar and ultraviolet radiation. IARC Monogr Eval Carcinog Risks Hum 2012; 100D: 1-68.

4 Albert MR, Ostheimer KG. The evolution of current medical and popular attitudes toward ultraviolet light exposure: part 3. J Am Acad Dermatol 2003; 49: 1096-1106.

5 Warthan MM, Sewell DS, Marlow RA, et al. The economic impact of acute sunburn. Arch Dermatol 2003; 139: 1003-1006.

6 Centers for Disease Control and Prevention. Sunburn and sun protective behaviors among adults aged 18 29 years--United States, 2000-2010. MMWR Morb Mortal Wkly Rep 2012; 61:317-322.

7 Buller DB, Cokkinides V, Hall HI, et al. Prevalence of sunburn, sun protection, and indoor tanning behaviors among Americans: review from national surveys and case studies of 3 states. $J$ Am Acad Dermatol 2011; 65 (5 Suppl 1): S114-S123.

8 Dobbinson SJ, Wakefield MA, Jamsen KM, et al. Weekend sun protection and sunburn in Australia trends (1987-2002) and association with SunSmart television advertising. Am J Prev Med 2008; 34: 94-101.

9 Rogers C, Kvaskoff M, DiSipio T, et al. Prevalence and determinants of sunburn in Queensland. Health Promot J Austr 2009; 20: 102-106.

10 Queensland Health. Self reported health status 2009-2010: Queensland summary report. Brisbane: Queensland Health, 2011. http:// www.health.qld.gov.au/ph/Documents/epi/ srhs0910qldsummary.pdf (accessed Feb 2013).

11 Brown WJ, Burton NW, Marshall AL, Miller YD. Reliability and validity of a modified selfadministered version of the Active Australia physical activity survey in a sample of mid-age women. Aust N Z J Public Health 2008; 32: 535-541.

12 National Health and Medical Research Council. Dietary guidelines for Australian adults. Canberra: NHMRC, 2003. http://www.nhmrc.gov. au/files nhmrc/publications/attachments/ n33.pdf (accessed Feb 2013)

13 Department of Health and Ageing. National physical activity guidelines for adults. Canberra: DoHA, 1999. (Publication No. PHY 09.) http:// www.health.gov.au/internet/main/publishing. nsf/content/BC3101BIFF200CA4CA256F9700 154958/\$File/adults_phys.pdf (accessed Feb 2013).

14 Australian Bureau of Statistics. Statistical geography Volume 1- Australian standard geographical classification (ASGC). Canberra: ABS, 2006. (ABS Cat. No. 1216.0.) http:// www.abs.gov.au/AUSSTATS/abs@.nsf/ allprimarymainfeatures/BD1B52D132D130E7CA 2573630012F67B? opendocument (accessed Feb 2013)

15 Australian Bureau of Statistics. Census of population and housing: Socio-Economic Indexes for Areas (SEIFA), Australia - data only, 2006. Canberra: ABS, 2008. (ABS Cat. No. 2033.0. 55.001.) http://www.abs.gov.au/AUSSTATS/ abs@.nsf/Lookup/2033.0.55.001Main+Features 12006?OpenDocument (accessed Feb 2013).

16 Erdmann F, Lortet-Tieulent J, Schüz J, et al. International trends in the incidence of malignant melanoma 1953-2008--are recent generations at higher or lower risk? Int J Cancer 2013; 132: 385-400.

17 Jardine A, Bright M, Knight L, et al. Does physical activity increase the risk of unsafe sun exposure? Health Promot J Austr 2012; 23: 52-57.
OPIOID THERAPY SHOULD ONLY BE PRESCRIBED AS PART OF A MULTIMODAL PAIN MANAGEMENT PLAN. TARGIN" tablets MINIIMUII PRODUCT INFORIMATION. INDICATIONS The management of moderate to severe chronic pain unresponsive to non-narcotic analgesia. The naloxone component in a fixed combination with oxycodone is ind cated for the therapy and/or prophylaxis of opioid-induced constipation. CONTRAINDICATIONS Hypersensituity to opioids, naloxone and any of the excipients or any situation where opioids are contraindicated, moderate to severe hepatic impairment severe respiratory depression with hypoxia, elevated carbon dioxide levels in the blood, cor pulmonale, cardiac arrinythmias; uncontrolled bronchial asthma, severe chronic obstructive pulmonary disease; non-opioid induced paralytic lleus, pregnancy, lactation, severe CNS depression; increased cerebrospinal or intracranial pressure, brain tumour or head inury (due to the risk of increased intracranial pressure); uncontrolled convulsive disorders suspected surgical abdomen, delaved gastric emptying, alcoholism; delinum tremens, concurrent administration of MAO-inhibitors and for 2 weeks after their cessation. PRECAUTIONS Mostimportanthazard of opioid preparations is respiratory depression occurs most frequently in overdose situations, the elderly, the deblitated and in those suffering from condtions accompanied by hypoxia when even moderate doses may be dangerous. Use with extreme caution in patients with substantially decreased respiratory reserve, preexisting respiratory depression, chronic obstructive pulmonary disease. Use with caution in hypothyroidsm (may need to reduce dose); elderly, infirm or debilitated patients, mild hepatic impairment, renal impairment, severely impaired pulmonary function, opioid dependence, hypotension, hypertension hypovolaemia; billary tract dsease; pancreatifis, inflammatory bowel disorders, prostatic hypertrophy, adrenocortical insufficiency (Addison's disease); toxic psychosis; myxoedema; opioid-induced paralytic leus: pre-existing cardiovascular disease; epileptic disorder or predisposition to convulsions, patients on long-term higher doses of opioids switching to TARGIN* tablets, chronic non-cancer pain, prior history of substance abuse. Not recommended in patients with galactose intolerance, Lapp lactase deficiency or glucose-galactose malabsorption; for the treatment of withdrawal symptoms, patients with cancer associated with peritoneal carcinomatosis or sub-occlusive syndrome in advanced stages of digestive and pelvic cancers. Tolerance and physical dependence tend to develop upon repeated administration. Withdraw gradually. Parenteral or intranasal abuse in opioid-dependent indviduals is expected to produce marked withdrawal symptoms. Parenteral venous iniection may be fatal. Reduce dosage to $1 / 3$ to $\frac{1}{2}$ of the usual dose in elderly patients who are infirm or debilitated and in patients with renal failure (Clcr $<60 \mathrm{~mL} / \mathrm{min}$ ) or mild hepatic impairment. May impair ability to drive and operate machinery. May produce positive results in sports agency drug tesfing procedures. Not recommended for immediate pre-operative use and post-operative for 24 hours after surgery Do not use within 24 hours of cordotomy or other pain-relieving surgery. INTERACTIONS Anticholinergic agents, anthypertensives, CNS depressants (antidepressants, sedatives, hypnotics, general anaesthetics, phenothiazines or other tranquilizers, alcohol, other opioids, anti-histamines, anti-emetics, neuroleptics eic.), coumarin derivatives, meloclopramide, non-selective MAOIs or within 14 days of stopping treatment (caution is advised with selective MAOIs) neuromuscular blocking agents, opioid agonist analgesics and mixed agonistantagonist analgesics, drugs that affect the P450 enzyme system (CYP3A4, CYP2D6). ADVERSE EFFECTS Typical of full opioid agonists and tend to reduce with time. Common side effects (incidence $21 \%$ ) include agitation, anorexia, asthenic conditions, abdominal pain, bronchospasm, chills, constipation, decrease in blood pressure, diarrhoea dizziness, drug withdrawal syndrome, dry mouth, dyspepsia, faintness, fever, gastrits, headache, hepatic enzymes increased, hiccup, hot flush, hyperhidrosis, insomnia, mood changes, muscle spasms, muscle twitching myalgia, nausea, orthostatic hypotension, pharyngtis, pruritus, rash, somnolence, ureteric spasm, urinary abnormalites, urinary tract infection, vertigo, voice alteration, vomiting. DOSAGE AND ADMINISTRATION Must be swallowed whole and not broken, chewed or crushed. Taking broken, chewed or crushed TARGIN tablets could lead to the rapid release and absorption of a potentially toxic dose of oxycodone that could be fatal. Adults: Usual starting dose (opioid-naive patients, or patients with moderate to severe chronic pain uncontrolled by weaker opioids): one $10 / 5$ mg TARGIN" tablet 12-hourly. Patients with renal or mild hepatic impairment one $5 / 2.5 \mathrm{mg}$ TARGIN tablet 12-hourly. Ttrate cautiously (every 1-2 days if necessary) to achieve pain relief. Maximum recommended daly dose: 80,40 $\mathrm{mg}$ (one $40 / 20 \mathrm{mg}$ TARGIN" tablet 12-hourly). Children: Not recommended in patients below 12 years of age. DATE OF FIRST INCLUSION IN ARTG 12 May 2010. DATE OF MOST RECENT AMENDMENT 28 December 2011. REFERENCES: 1. TARGIN tablets Product Information, December 2011.2. MeissnerW etal. Eur J Pain 2009,13(1) 56-64. 3. Lowenstein 0 et al. Expert Opin Pharmacother 2009,10/4):531-543.4. Lowenstein 0 et al. BMC Clin Pharmacol 2010,10:12. 5. Sandner-Kiesling A et al. Int J Clin Pract 2010,64(6):763-774. 6. Simpson K et al. Curr Med Res Opin 2008:24(12):3503-3512. 7. Vondrackova D et al. J Pain 2008:9(12):11441154. (0. TARGIN is a Registered Trademark. Mundipharma Pty Limited ABN 87081322 509, 50 Bridge Street, Sydney, NSW 2000. Tel: 1800188 009 Saatchi \& Saatchi Health MUNO210MUA ORBIS AU-1664 Mar 13 
Research

TARGIN 